\title{
Common Bile Duct
}

National Cancer Institute

\section{Source}

National Cancer Institute. Common Bile Duct. NCI Thesaurus. Code C12698.

Bile ducts are passageways that carry bile. Two major bile ducts come together into a "trunk"-the common bile duct which empties into the upper part of the small intestine (the part next to the stomach). 